\title{
A conquista de 'espaço(s)' físico e intelectual para uma nova área disciplinar na Argentina
}

\author{
The conquest of physical and intellectual 'space(s)' \\ for a new disciplinary area in Argentina
}

\author{
Elisabete Pereira \\ Doutoranda do Programa de Doutoramento em História e Filosofia da Ciência (especialidade Museologia) \\ do Centro de Estudos de História e Filosofia da Ciência/Universidade de Évora. \\ elisabetejspereira@gmail.com
}

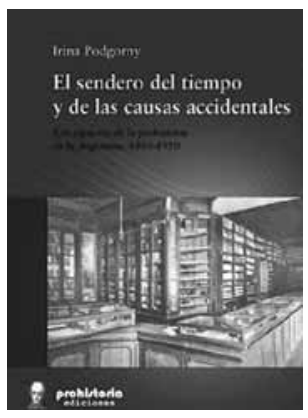

PODGORNY, Irina. EI sendero del tiempo y de las causas accidentales: los espacios de la prehistoria en la Argentina, 18501910. Rosario: Prohistoria, 2009. 336p. $\square$ ontribuindo para a história da arqueologia e da ciência argentina, esse livro transporta-nos para um período em que a sociedade se viu confrontada com a questão da antiguidade da espécie humana e em que os círculos científicos ocidentais conjugavam para o seu esclarecimento os conhecimentos da geologia, da estratigrafia e da paleontologia. Expondo a formação de uma geração de cientistas, a autora desenvolve os debates e as tensões científicas, sociais e políticas associadas à construção e estruturação de um novo horizonte temporal para a história da humanidade. Em causa estavam as condições que permitiam o contacto com os novos conhecimentos e a forma como várias personalidades usaram as novas perspectivas e colecções científicas para conquistar 'espaço(s)' físico e intelectual para uma nova área disciplinar. El sendero del tiempo y de las causas accidentales mostra-nos como a formação das primeiras coleções de objetos préhistóricos argentinos praticamente coincidiu com a fase de validação das descobertas de Boucher de Perthes. Atendendo aos acervos bibliográficos do Museo Público de Buenos Aires, da Academia de Ciencias de Córdoba e da Sociedade Científica Argentina, Irina Podgorny mostra-nos como essas instituições constituíram canais de divulgação científica e espaços físicos de recepção e de divulgação das novas teorias que expunham a antiguidade do homem durante o século XIX.

Numa investigação que cruza a história intelectual da ciência e a história dos museus, a autora revela como o início do debate sobre as origens do homem remete a um contexto internacional de formação, competição e comércio de coleções paleontológicas conjugado com a ação de 'intérpretes locais da natureza'. É também um contexto em que os estados modernos sentem a necessidade de assumir a curadoria das 'coleções nacionais', sendo a projeção de edifícios e filosofias para estruturar e divulgar os novos elementos sobre a história nacional conjugada com a ação de cientistas, políticos e também colecionadores particulares, cujos acervos assumiam uma significativa relevância científica. No processo influíam também os referentes museográficos europeus e norte-americanos e a ascendência dos museus itinerantes, fomentadores da divulgação científica e da prática do colecionismo. 
Estando em causa a passagem da atitude de colecionar da esfera individual para a esfera estatal, nessa investigação a autora prossegue a questão da relação entre colecionador, colecção e Estado, já abordada em outros trabalhos (Podgorny, 2002). Para entender a ação científica e institucional das várias personalidades envolvidas, Irina Podgorny revela-nos aspectos do seu contexto social, do seu processo de educação formal e informal, os espaços de sociabilidade, as formas e os canais de projeção no espaço público americano e europeu, evidenciando a construção da sua consagração. Nessa narrativa destacam-se atores sociais e científicos como o naturalista alemão Hermann Burmeister, que se tornou diretor do Museu de Ciências Naturais de Buenos Aires, e também Estanislao Zeballos, Francisco Moreno, Carlos Berg e sobretudo Florentino Ameghino. Uma figura muito dinâmica e polêmica, cujas teses celebrizaram uma original imagem do homem pré-histórico argentino abrigado nas carapaças do gliptodonte (p.171).

Para a interpretação do percurso dessas individualidades e do seu contributo científico, Irina Podgorny, pesquisadora do Consejo Nacional de Investigaciones Científicas y Técnicas no Arquivo Histórico do Museu de La Plata, utilizou as genealogias de publicações abrangidas nesse processo epistemológico: as publicações dos cientistas envolvidos e os periódicos de instituições argentinas - Museo Nacional, Museo de La Plata, Museo Público da Província de Buenos Aires, Sociedad Científica Argentina, Academia Nacional de Ciencias de Córdoba - em conjugação com monografias, boletins e revistas europeias. Os acervos epistolares, reveladores da troca de conhecimento, cooperação científica, rivalidades e polêmicas, foram outro dos recursos utilizados pela autora. Surpreendente o uso que fez de fontes como os periódicos humorísticos (p.43, 203) para evidenciar as atmosferas intelectuais, destacandose também a importância das fotografias e das reportagens do jornal A Patria Argentina, em 1883, sobre o popular Museu Bennati - recursos fundamentais para complementar a apreensão do ambiente institucional e civil do século XIX.

No seguimento de anteriores investigações sobre controvérsias científicas ligadas a coleções e museus argentinos (Podgorny, Lopes, 2008) Irina Podgorny destaca agora em El sendero del tiempo y de las causas accidentales os contextos e os atores envolvidos na estruturação disciplinar da pré-história na segunda metade do século XIX e primeira década do século XX.

$\mathrm{Na}$ primeira parte desse livro encontramos o contexto historiográfico em que os museus se afirmam como espaço institucionalizador das ciências e símbolo material do cume da civilização. Um período em que foi necessário estabelecer vocabulário para definir um período de 'história sem palavras' e em que se estruturam os primeiros 'catálogos, gestos e edifícios' para a nova disciplina. Podgorny evidencia a forte ascendência eurocentrista, em que, apesar da distância geográfica e geológica, o modelo francês é copiado e enriquecido com algumas originalidades. A segunda parte dessa investigação começa por evidenciar o fato de, na Argentina, o interesse pela pré-história não poder separar-se da formação das coleções paleontológicas. Nessa viagem à segunda metade do século XIX, vemos como são prolíferas as deslocações intercontinentais e o estabelecimento de europeus em busca dos fósseis argentinos destinados a instituições e exposições públicas, e a forma como surge o debate e a tentativa de legitimação dos dados que comprovavam a antiguidade do homem americano. Esses dados cabiam no amplo conceito de história natural, em que junto dos fósseis de animais extintos se podiam também estudar os 'selvagens contemporâneos'. Na Argentina, como no 
Brasil e no mundo ocidental, a questão da antiguidade do homem integra-se nos desígnios da afirmação da memória da nação. As coleções e os museus tornavam-se fundamentais para consolidar e divulgar os novos conhecimentos decorrentes de um intenso intercâmbio de objetos, documentos, conhecimentos e pessoas. É um ambiente de protagonistas masculinos, em que interagem os naturalistas viajantes, os informadores locais, os cientistas e também os charlatães e os políticos.

Essa investigação, que integra a coleção "Historia de la Ciencia", dirigida pela autora na editora Prohistoria de Rosário, Argentina, vem também enfatizar as já questionadas oposições historiográficas entre centro e periferia bem como entre amadores e profissionais.

Irina Podgorny é antropóloga, doutora em ciências naturais pela Universidade Nacional de La Plata, professora de história da ciência na Universidade Virtual de Quilmes e pesquisadora do Consejo Nacional de Investigaciones Científicas y Técnicas no Arquivo Histórico do Museo de La Plata. Foi professora convidada do Museu de Astronomia e Ciências Afins (Rio de Janeiro, 2001), da Universidade de Paris VII (2008) e da École des Hautes Études en Sciences Sociales (2009). Recebeu os prêmios Estímulo da Fundação Bunge y Born (2001), foi bolsista Humboldt (2002-2003) e pesquisadora visitante do Instituto Max Planck de História da Ciência (Berlim, 2009-2010). É autora, entre outros, dos livros citados nas referências e de Arqueología de la educación: textos, indicios, monumentos: la imagen del indio en el mundo escolar (Buenos Aires, Sociedad Argentina de Antropología, Colección Tesis Doctorales, 1999), Los viajes en Bolivia de la Comisión Científica Italiana (Santa Cruz de la Sierra, Fundación Nova, Biblioteca Cruceña, 2011). Orienta várias teses e projetos de pesquisa no Museu de La Plata, incluindo um projeto de salvaguarda de arquivos financiado pela British Library. Publicou em revistas como Osiris, Science in Context, Redes, Asclepio, Trabajos de Prehistoria, Journal of Spanish Cultural Studies etc.

\section{REFERÊNCIAS}

PODGORNY, Irina; LOPES, Maria Margaret. El desierto en una vitrina: museos e historia natural en la Argentina, 1810-1910. Ciudad de México: Limusa. 2008.
PODGORNY, Irina. El argentino despertar de las faunas y de las gentes prehistóricas: coleccionistas, estudiosos, museos y universidad en la creación del patrimonio paleontológico y arqueológico nacional, 1875-1913. Buenos Aires: Universidad de Buenos Aires/Libros del Rojas. 2002.

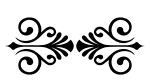

